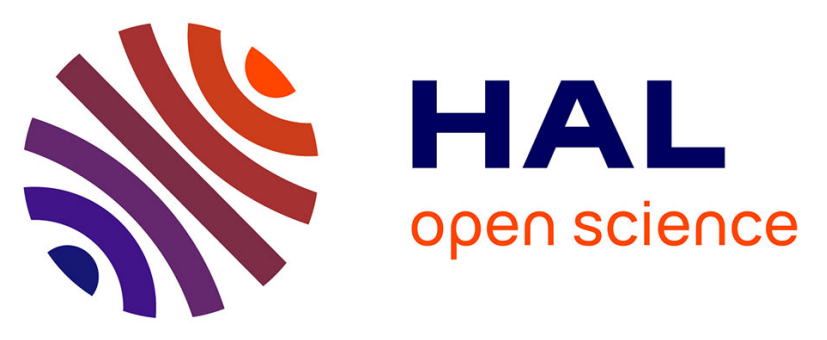

\title{
Surface functionalization of ultrananocrystalline diamond using atom transfer radical polymerization (ATRP) initiated by electro-grafted aryldiazonium salts
}

Tarik Matrab, Mohamed Chehimi, Jean-Paul Boudou, F. Benedic, J. Wang, N.N. Naguib, J.A. Carlisle

\section{To cite this version:}

Tarik Matrab, Mohamed Chehimi, Jean-Paul Boudou, F. Benedic, J. Wang, et al.. Surface functionalization of ultrananocrystalline diamond using atom transfer radical polymerization (ATRP) initiated by electro-grafted aryldiazonium salts. Diamond and Related Materials, 2006, 15, pp.639 - 644 . 10.1016/j.diamond.2005.11.024 . bioemco-00144853

\section{HAL Id: bioemco-00144853 \\ https://hal-bioemco.ccsd.cnrs.fr/bioemco-00144853}

Submitted on 5 May 2007

HAL is a multi-disciplinary open access archive for the deposit and dissemination of scientific research documents, whether they are published or not. The documents may come from teaching and research institutions in France or abroad, or from public or private research centers.
L'archive ouverte pluridisciplinaire HAL, est destinée au dépôt et à la diffusion de documents scientifiques de niveau recherche, publiés ou non, émanant des établissements d'enseignement et de recherche français ou étrangers, des laboratoires publics ou privés. 


\title{
Surface functionalization of ultrananocrystalline diamond using atom transfer radical polymerization (ATRP) initiated by electro-grafted aryldiazonium salts
}

\author{
T. Matrab ${ }^{\mathrm{a},}$ M.M. Chehimi ${ }^{\mathrm{a}, *}$, J.P. Boudou ${ }^{\mathrm{b}}$ F. Benedic ${ }^{\mathrm{c}}$, J. Wang ${ }^{\mathrm{d}}$ N.N. Naguib ${ }^{\mathrm{d}}$ J.A. Carlisle ${ }^{\mathrm{d}}$ \\ a ITODYS, Université Paris 7-CNRS (UMR 7086), 1 rue Guy de la Brosse, 75005 Paris, France \\ ${ }^{\mathrm{b}}$ Université. Pierre et Marie Curie UMR 7618 Bio EMCo- Case 124, 4 place Jussieu, 75252 Paris Cedex 05 - France \\ c LIMHP-UPR 1311 CNRS, Université Paris 13, 99 av. J.B. Clément, 93430 Villetaneuse, France \\ ${ }^{\mathrm{d}}$ Material Science Division and Center for Nanoscale Materials, Argonne National Laboratory, Argonne, Illinois 60439, USA
}

\begin{abstract}
The integration of organic adlayers with diamond surfaces imparts many new properties to diamond materials, including lubrication, optical response, chemical sensing, and biocompatibility. The development of new immobilization chemistries is required in which organic layers are covalently attached to the diamond surface. Poly(methyl methacrylate) and polystyrene brushes (PMMA, PS, respectively) were grown from the surfaces of ultrananocrystalline diamond (UNCD) thin films that were modified by the electrochemical reduction of the diazonium salt $\mathrm{BF}_{4}-+\mathrm{N}_{2-}$ $\mathrm{C}_{6} \mathrm{H}_{4}-\mathrm{CH}\left(\mathrm{CH}_{3}\right)-\mathrm{Br}$. The grafted $-\mathrm{C}_{6} \mathrm{H}_{4}-\mathrm{CH}\left(\mathrm{CH}_{3}\right)-\mathrm{Br}$ species were effective in promoting surface initiated atom transfer radical polymerization (SI-ATRP) of the vinyl monomers. Attempts to perform SI-ATRP from undoped diamond films produced by microwave plasma assisted chemical vapour deposition (MPACVD) process was rather unsuccesful due to a very low extent of electrochemical modification by the brominated aryl diazonium salts. The formation of the polymer brushes was confirmed by XPS. The polymer brushes were further evaluated as adsorbents for human serum albumin (HSA) used as a model protein. Protein adsorption decreased in the order PS>PMMA, that is the decreasing trend of hydrophobic character.
\end{abstract}

Keywords: ATRP; Diazonium salts; Polymer brushes; Ultrananocrystalline diamond (UNCD); Protein adsorption

\section{Introduction}

Atom transfer radical polymerization (ATRP) is one of the most investigated methods of controlled radical polymerization as it can be performed with a variety of functional monomers, at room temperature and in aqueous or organic solvents [1]. In addition, ATRP can be initiated from surfaces for several purposes [2]. The resulting polymer brushes can facilitate the preparation of hybrid materials [3] or biocompatible surfaces [4]. ATRP can be surface-initiated by using, e.g., initiatorterminated silanes [1] and thiols [5], photo-brominated surfaces [6], or macroinitiators [7].

Recently, we have shown that ATRP of vinyl monomers can be surface-initiated by electro-grafted brominated aryl species based on diazonium salts [8]. The use of aryl diazonium salts is

\footnotetext{
* Corresponding author. Tel.: +33 144276809; fax: +33 144276814.

E-mail address: chehimi@paris7.jussieu.fr (M.M. Chehimi).
}

indeed an elegant way to modify conducting or semi-conducting substrates such as metals, carbon and hydrogenated silicon [9]. The grafted species can bear a variety of functional groups (e.g., alkyl, and halides) depending on the target applications such as polymer coatings, molecular junctions in electronic circuits, and the detection of molecules of biomedical interest.

The motivation for using aryl diazonium salts to surface initiate ATRP (SI-ATRP) is to design, for example, a salt which is an analogue of 1-phenylethyl bromide (1-PEBr), a frequently used bulk solution ATRP initiator [1]. The corresponding $\mathrm{BF}_{44}, \mathrm{~N}_{2}-\mathrm{C}_{6} \mathrm{H}_{4}-\mathrm{CH}\left(\mathrm{CH}_{3}\right)-\mathrm{Br}$ salt could readily be electrochemically reduced on glassy carbon (GC) and iron [8]. The resulting $-\mathrm{C}_{6} \mathrm{H}_{4}-\mathrm{CH}\left(\mathrm{CH}_{3}\right)-\mathrm{Br}$ group (1) grafted onto iron permitted the growth of strongly adhering polystyrene, poly(methyl methacrylate) and poly(n-butylacrylate) brushes (PS, PMMA and PBA, respectively) [8].

Performed successfully on metals and carbon, it is expected that the "ATRP/diazonium salt"' protocol can be extended to 
ultrananocrystalline diamond (UNCD). UNCD thin films have a variety of interesting bulk and surface properties and potential applications such as low friction wear resistance coatings [10], coatings for biomedical implants [11,12], selective biosensors [13,14], biointerfaces [15], electrodes for the study of the direct electron transfer to proteins [16], and biocompatible surfaces [17]. UNCD films also have the superior properties of diamond such as extreme hardness and mechanical strength, favorable tribological properties, high room-temperature n-type conductivity (when doped with nitrogen) [18], extreme microstructural and morphological stability, and electrochemical properties including high overpotentials for both oxygen and hydrogen evolution $[19,20]$. The enhanced conductivity of UNCD is due to nitrogen doping at the grain boundaries (GB). In UNCD, the grains are small (less than $15 \mathrm{~nm}$ in an amount of no less than $10^{10}$ atoms $/ \mathrm{cm}^{3}$ ) and the number of GBs, where the effective nitrogen doping occurs, is large. The potential for using n-type UNCD and other forms of conducting diamond films as electrochemical biointerfaces with soft materials motivates much of the work reported here [21-23]. However, several UNCD applications require control of its surface properties such as surface chemistry, wettability, optical properties, etc. The surface modification of synthetic diamond materials has been investigated by several groups. Two general approaches have been studied: direct chemical functionalization of hydrogen-terminated surface [24,25] or application of preteatment method that renders the surface hydrophobillic (by generation of oxygen-containing surface functionalities) $[26,27]$. In the first approach, the hydrophobic hydrogenterminated surfaces were functionalized, either photochemically by UV excitation of halogen gases [24], or alkenes [25] thereby introducing chloro-, fluoro-, or aminoalkyl groups, or chemically by thermal decomposition of benzoyl peroxide [28]. In the second approach, oxygen-containing functional groups were introduced onto polycrystalline diamond surfaces by oxygen plasma treatment, anodic polarization, or by strong oxiding acids. The hydrophilic surface can then be modified using standard silane coupling agents [29].

Recently, Carlisle's group has demonstrated the surface modification of UNCD thin films via electrochemical reduction of aryl diazonium salts [30]. It was shown that grafting of 3,5-dichlorophenyl groups renders the UNCD surface hydrophobic, whereas the attachment of 4-aminophenyl groups (obtained by a two-step approach) makes the surface relatively hydrophilic.

In this paper we explore the possibility to use electro-grafted aryl species on undoped and $\mathrm{N}$-doped ultrananocrystalline diamond thin films for the surface-initiated ATRP of vinyl monomers, namely methyl methacrylate and styrene, in the presence of the $\mathrm{Cu}(\mathrm{I})$ catalyst and the ligands pentamethylenediethylenetriamine (PMDETA) or bi-pyridine. PMMA and PS brushes grown from electrochemically modified UNCD were characterized by XPS. The polymer-modified UNCD plates were further evaluated as adsorbents for human serum albumin (HSA) at pH 5 in relation to the hydrophobic character of the grafted polymer brushes.

\section{Experimental}

The preparation of N-containing conductive UNCD (hereafter called d-UNCD, where d stands for doped) thin film on Si wafers has been described in [31]. d-UNCD thin films were deposited on highly conducting n-type $\mathrm{Si}(111)$ substrates (Wafernet Inc., San Jose, CA) using microwave plasma assisted chemical vapor deposition (MPACVD) [CYRANNUS I reactor from IPLAS (Innovative Plasma Systems, Inc., Triosdorf, Germany)]. A mixture of $\mathrm{CH}_{4}, \mathrm{Ar}$ and $\mathrm{N}_{2}$ gases was used for the microwave discharge. The d-UNCD films used in this work were deposited with $5 \%$ volume ratio of nitrogen in the plasma, and a flow rate of $1 \mathrm{sccm}$ was maintained for $\mathrm{CH}_{4}$. The substrate temperature was about $800^{\circ} \mathrm{C}$, and the input microwave power was about $1.3 \mathrm{~kW}$.

Undoped nanocrystalline diamond films (u-UNCD) were produced by MPACVD process in a home-made bell jar reactor extensively described in previous papers [32]. (100)-oriented silicon wafers of approximately $7 \mathrm{~cm}^{2}$ in size were used as substrates. Prior to the diamond deposition, the Si substrates were ultrasonically abraded for $1.0 \mathrm{~h}$ in a suspension of diamond powder with a grain size of around $40 \mu \mathrm{m}$ in ethanol [33]. The growth was achieved using a $96 \% \mathrm{Ar} / 3 \% \mathrm{H}_{2} / 1 \% \mathrm{CH}_{4}$ feed gas, under $600 \mathrm{~W}$ microwave power, $200 \mathrm{hPa}$ pressure and $250 \mathrm{sccm}$ total gas flow rate, while maintaining the substrate temperature around $1120 \mathrm{~K}$. The deposition time was set at 3.0 $\mathrm{h}$ which was suitable to obtain continuous films of approximately $2 \mu \mathrm{m}$ in thickness. The deposition conditions mentioned above are appropriate for synthesising nanocrystalline diamond layers with a grain size ranging from 10 to $15 \mathrm{~nm}$ and a surface roughness (Rms parameter) between 20 and $25 \mathrm{~nm}$, keeping an acceptable diamond purity [34]. After the deposition process, the diamond/Si wafers were cut in order to obtain identical samples of $1 \times 2 \mathrm{~cm}^{2}$ area.

The synthesis and electrochemical reduction of D1 on GC is detailed in Ref. [8]. It is to note that the surface conductivity of u-UNCD $[18,35]$ was responsible for the weak extent of electrochemical reduction of D1 at the surface of u-UNCD.

The growth of brushes on D1-modified ultrananocrystalline diamond was performed as follows : a $100 \mathrm{~mL}$ Schlenk flask containing a magnetic stir bar and sealed with a rubber septum was deoxygenated by vacuum followed by back-filling with nitrogen three times. The $\mathrm{CuBr}$ powder $\left(1.36 \times 10^{-3} \mathrm{~mol}\right.$, Aldrich) and the (UNCD +1) plates were introduced into the flask under a nitrogen flow. A mixture containing distilled styrene (106 x 10 $0^{-3} \mathrm{~mol}$, Aldrich), 1 -PEBr $\left(1.36 \times 10^{-3} \mathrm{~mol}\right.$, Aldrich) and bipyridine (Bpy, $4.8 \times 10^{-3} \mathrm{~mol}$, Aldrich), previously degassed, was added to the polymerization flask using a double-tipped needle under a nitrogen flow. The flask was placed in an oil bath at $110^{\circ} \mathrm{C}$ for $5 \mathrm{~h}$. The polymerization was stopped by cooling and opening the flask to expose the catalyst to air. PMMA brushes were prepared as in Ref. [8].

For PS brushes, the target $M_{n}$ and $M_{w} / M_{n}$ were $71,000 \mathrm{~g} / \mathrm{mol}$ and 1.22 [36], respectively $\left(\mathrm{M}_{\mathrm{n}}\right.$ : number average molecular weight and $\mathrm{M}_{\mathrm{w}}$ is the weight average molecular weight). 


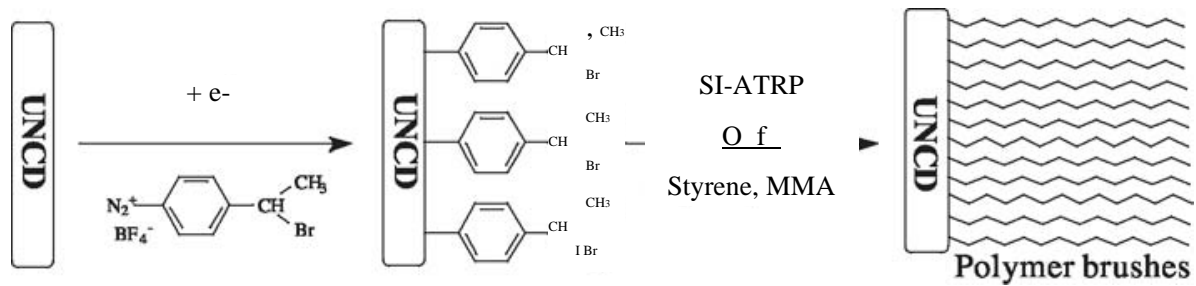

Scheme 1. Growth of polymer brushes from UNCD surfaces modified by electrografted ATRP initiators based on aryl diazonium salts.

UNCD+ 1 +brushes were incubated overnight in $0.5 \mathrm{mg} /$ $\mathrm{ml}$ aqueous solutions of HSA (Sigma) buffered at $\mathrm{pH} 5$ using $0.1 \mathrm{M}$ acetic acid/acetate. The plates were then thoroughly rinsed by $5 \%$ volume ration aqueous solution of Tween 20 (Aldrich) and then with distilled water.

XPS spectra were recorded as mentioned in [8] using a Thermo VG Scientific ESCALAB 250 system fitted with a monochromatic Al Ka X-ray source $(1486.6 \mathrm{eV})$. The spot size was $650 \mathrm{Am}$ for standard analysis. The samples were mounted onto conductive double-sided adhesive tapes which enabled us to perform the analyses without the use of the flood-gun, usually employed for insulating materials, even in the case of the u-UNCD samples. Moreover, the raw XPS data obtained with u-UNCD gave C1s spectra centred at $285 \mathrm{eV}$ without any noticeable shift due to static charging effect observed with insulating materials. This is in line with a surface conductivity mentioned in details elsewhere [35].

The lateral uniformity of the D1 electrografting and the growth of polymer brushes along the main axes of the plates were checked using a $400 \mathrm{Am} \mathrm{X}$-ray spot. This gives a macroscopic estimation of the uniformity, at a " 400 Am scale, of the grafted species.

\section{Results and discussion}

The modification of the UNCD substrates by the electrochemical reduction of brominated aryl diazonium salts and the subsequent SI-ATRP of a vinylic monomer is illustrated in Scheme 1. This method was performed in the presence of the sacrificial initiator 1-PEBr added in solution in order to increase the concentration of the $\mathrm{Cu}^{\mathrm{II}}$ complex and thus to better control the polymerization.

Fig. 1 shows XPS survey scans of the uncoated and polymer coated d-UNCD +1 plates. The main peaks C1s and O1s are centered at 285 and $530 \mathrm{eV}$, respectively. The corresponding high resolution C1s regions are shown in the insert. One can also detect Br3d at $71 \mathrm{eV}$ from the grafted aryl species 1 at the surface of d-UNCD+ 1 therefore underlying the successful modification of UNCD by the electrochemical reduction of D1.

The lateral uniformity of the diazonium electrografting and PMMA brush growth were investigated on the UNCD substrates. Fig. 2 shows the Br3d-Br3p region (Fig. 2a) from $d-U N C D+1$ and the $C 1$ s fine structure from dUNCD+1+PMMA (Fig. 2b). Both spectra were taken over a few millimeter lines. The spectra have from one spot to another the same structure and intensity which emphasizes a uniform

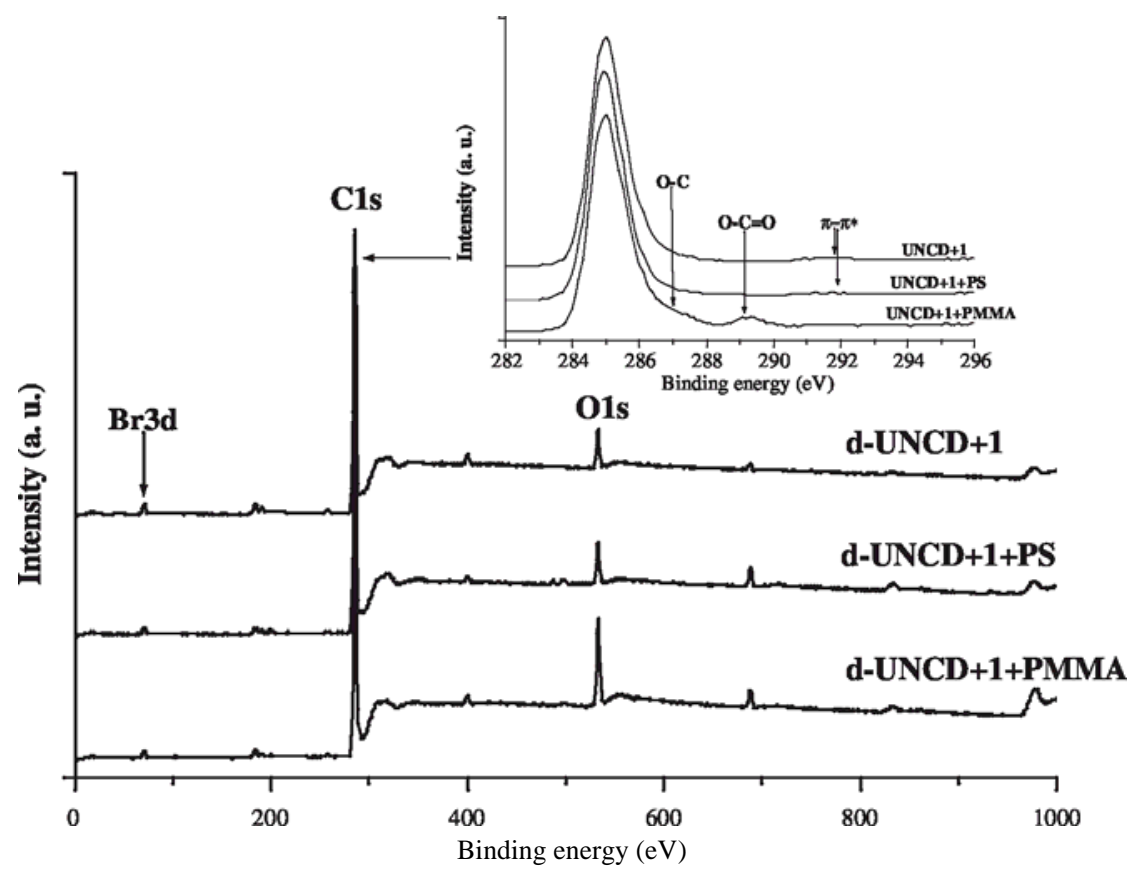

Fig. 1. Survey scans of N-doped diamond (d-UNCD+1) before and after growth of polymer brushes. The corresponding high resolution C1s regions are shown in insert. 

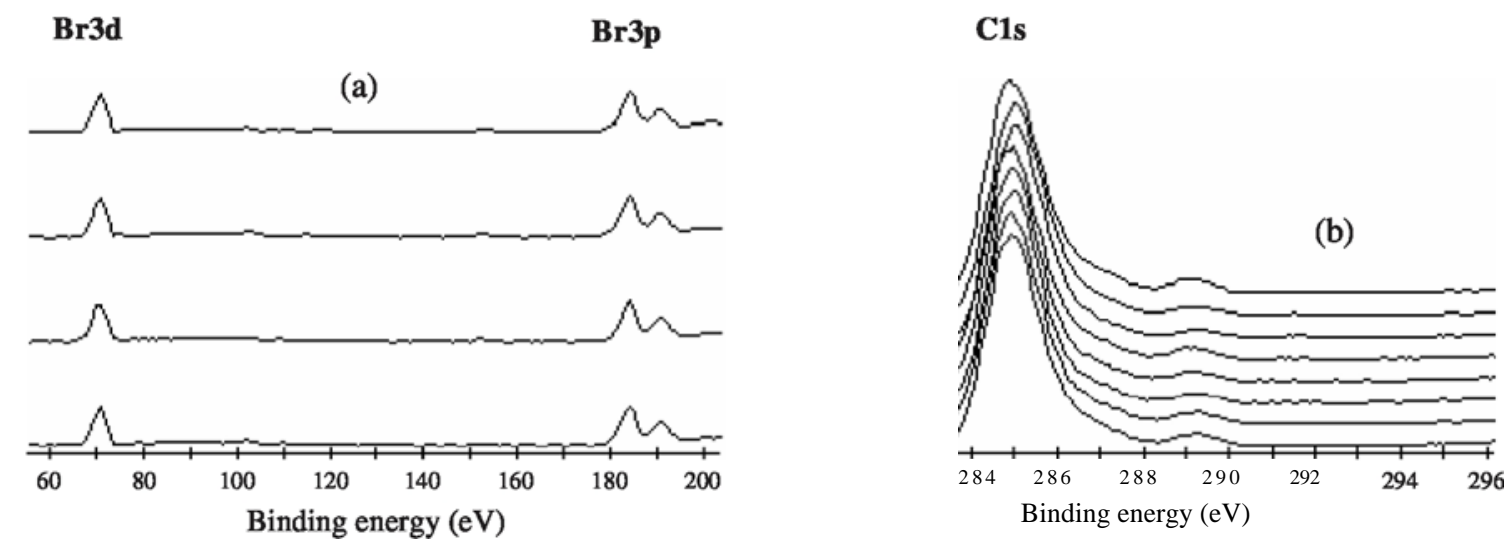

Fig. 2. Study of the lateral uniformity of (a) brominated aryl electrografting, and (b) PMMA chains growth by SI-ATRP on UNCD thin films.

electrografting of the brominated aryl diazonium and a subsequent uniform lateral growth of PMMA chains from the electrochemically modified UNCD.

Table 1 reports the surface chemical composition of materials in at.\%. The first important observation is that the bromine content of d-UNCD+ 1 is 17 times higher than for $\mathrm{u}$ UNCD plates. It follows that doping is an important procedure for the modification of diamond by aryl diazonium salts. In contrast to undoped UNCD, nitrogen-containing UNCD was observed experimentally to have conductivities approaching that of graphite and yet still be essentially phase-pure diamond [37].

It is clear that for d-UNCD, the growth of PMMA brushes results in a high oxygen content compared to PS brushes as there are two oxygen atoms per MMA repeat unit. Bromine is detected at the surfaces of PS and PMMA brushes grown from dUNCD+ 1 . This indicates that the polymer chains are terminated by bromine, in line with the principles of ATRP [1] and our recent study of polymer brushes grown from the surface of iron.

The contribution of the ester component and shake-up satellite to the C1s peaks of PMMA and PS at d-UNCD are $2.5 \%$ and $1 \%$, instead of $20 \%$ and $10 \%$, respectively. This indicates that the underlying d-UNCD massively contributes to the total C1s peak intensity, implying very thin polymer coatings ( $<10 \mathrm{~nm}$, the XPS sampling depth).

In the case of u-UNCD+1, the carbon and oxyen contents before and after growth of PMMA brushes are practically the same.

The detection of Br3d at $71 \mathrm{eV}$ reflects the presence of $\mathrm{CH}\left(\mathrm{CH}_{3}\right)-\mathrm{Br}$ moiety in the initiator and $\mathrm{C}-\mathrm{Br}$ bonds in polymer chain ends. Cl2p peak was detected, for polymer brushes, $200.0 \mathrm{eV}$ which corresponds to $\mathrm{C}-\mathrm{Cl}$ bonds. Thus, the polymeric chains could have a chlorine atom at the terminus.

Table 1

Surface chemical compositions of diamond plates as determined by XPS

\begin{tabular}{lccccccc}
\hline Materials & $\mathrm{C}$ & $\mathrm{O}$ & $\mathrm{N}$ & $\mathrm{Br}$ & $\mathrm{Cl}$ & $\mathrm{Cu}$ & $\mathrm{F}$ \\
\hline d-UNCD +1 & 92.1 & 4.41 & 1.81 & 0.85 & - & - & 0.29 \\
d-UNCD+1 +PS d- & 91.6 & 5.01 & 0.98 & 0.46 & 0.40 & 0.06 & 1.32 \\
UNCD+ 1 +PMMA u- & 86.2 & 10.3 & 1.37 & 0.59 & 0.17 & 0.04 & 1.28 \\
UNCD+1 & 93.7 & 2.12 & 1.21 & 0.05 & - & - & 2.32 \\
u-UNCD+ 1 +PMMA & 96.9 & 2.19 & 0.33 & 0.09 & - & 0.12 & 0.24 \\
\hline
\end{tabular}

N1s and F1s centered at 401 and $685 \mathrm{eV}$, respectively, are due to traces of supporting electrolytes, which have not been completely removed despite thorough rinsing. Whenever copper is detected, its surface proportion is negligibly small.

It is to note that copper (catalyst) is trapped in the polymer brushes in spite of thorough solvent washing.

As far as the C1s regions are concerned, the d-UNCD+1 exhibits a sharp peak centred at $285 \mathrm{eV}$ with a small component around $286.5 \mathrm{eV}$ due the $\mathrm{C}-\mathrm{Br}$ bonds and a slight degree of the surface oxidation and contamination. Interestingly, this $\mathrm{C} 1 \mathrm{~s}$ region has a $7 \mathrm{r}-7 \mathrm{r}$ * shake-up satellite due to the electrografted brominated aryl groups. For d-UNCD +1+ PS, the shake-up satellite, characteristic of PS, is also observed.

PMMA brushes impart the most significant changes to the $\mathrm{C} 1 \mathrm{~s}$ structure of d-UNCD +1 . Indeed, (i) the characteristic O$\mathrm{C}=\mathrm{O}$ component appears at $289 \mathrm{eV}$ together with a distinct component at $286.5 \mathrm{eV}$ due to $\mathrm{O}-\mathrm{CH}_{3}$ bonds; (ii) the shake-up satellite from the electrografted aryl type initiator is completely screened by the polymer overlayer.

It is important to note that the characteristic C1s features from PMMA above-mentioned are quasi absent from the uUNCD + 1 +PMMA surface, thus confirming the quantitative results reported in Table 1 on the quasi absence of polymer brushes at the surface of undoped diamond thin films.

Attachment of HSA to d-UNCD+1+PS and dUNCD + $1+$ PMMA was monitored using the change in the carbon, nitrogen and oxygen contents while considering the $\mathrm{C}$ 1s fine structure.

Fig. 3 displays the survey scans of d-UNCD+ $1+$ PS and dUNCD + 1 +PMMA after adsorption of HSA. Both surfaces have a massive increase in the oxygen contents due to the adsorbed protein. Though less clear, the N1s peaks are slightly better detected than in Fig. 1.

Before attachment of HSA, PS brushes have a C1s structure comparable to that of a pure PS with a main feature at $285 \mathrm{eV}$ and a shake-up satellite at $291.5 \mathrm{eV}$. After protein adsorption, two prominent shoulders were observed at 286.5 and $288 \mathrm{eV}$ corresponding to $\mathrm{C}-\mathrm{N} / \mathrm{C}-\mathrm{O}$ bonds and amide groups, respectively. For PMMA, the changes are less significant since PMMA has already oxidized carbon types $(\mathrm{C}-\mathrm{O}$ and $\mathrm{O}-\mathrm{C}=\mathrm{O}$ ) the components of which are centered at 286.5 and $289 \mathrm{eV}$, 


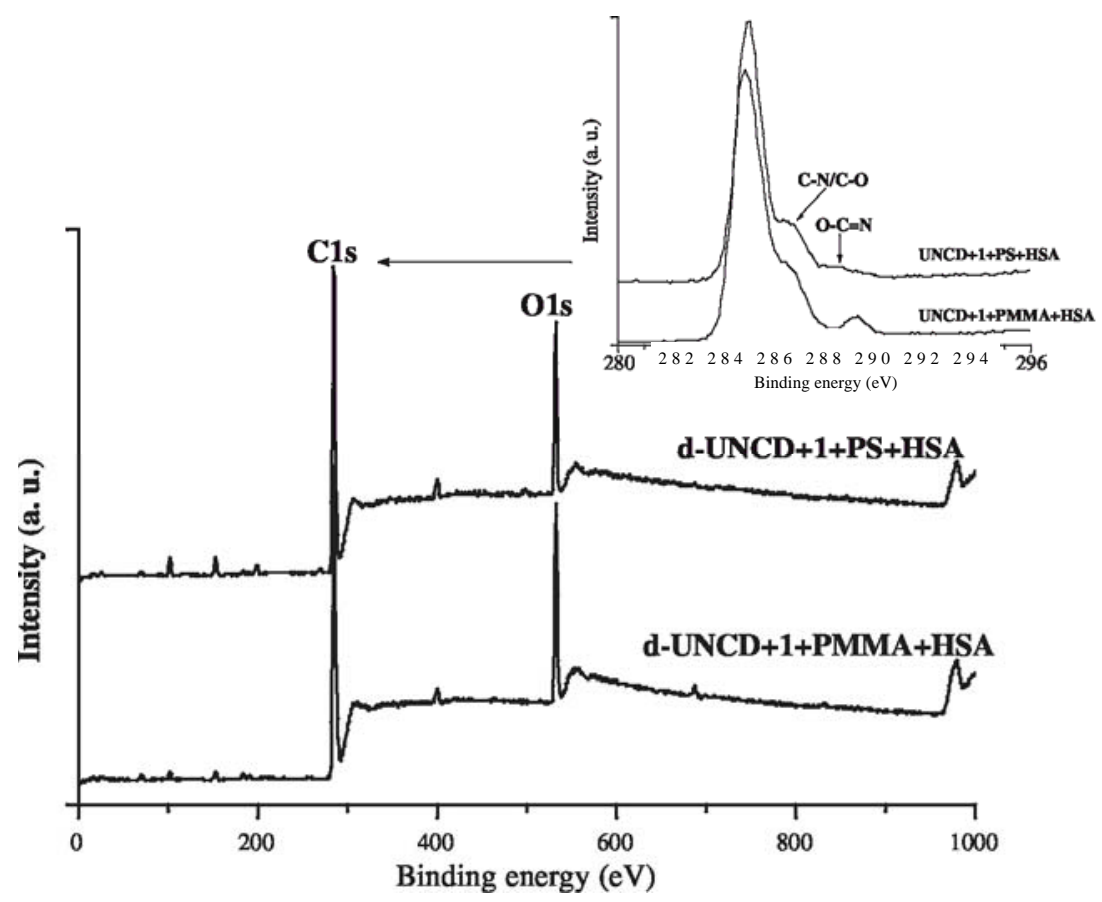

Fig. 3. Survey scans of d-UNCD+1+PS and d-UNCD+1+PMMA after protein attachment. The corresponding high resolution C 1s regions are shown in insert.

respectively. However, there is evidence for a small component at $288 \mathrm{eV}$ due to the peptidic linkages $(\mathrm{N}-\mathrm{C}=\mathrm{O})$.

A simple way to monitor protein adsorption onto dUNCD $+1+$ PS and d-UNCD+ $1+$ PMMA is to consider the surface $(\mathrm{O}+\mathrm{N}) / \mathrm{C}$ ratios before and after adsorption. Indeed, the contribution of the protein to the nitrogen and oxygen content is expected to be significant since each amino acid is linked to another via an amide group. Moreover, several aminoacids contain nitrogen and/or oxygen in their residues. Fig. 4 shows the variation of $(\mathrm{O}+\mathrm{N}) / \mathrm{C}$ for the PS and PMMA brushes due to protein adsorption. For d-UNCD+1+ PS, the $(\mathrm{O}+\mathrm{N}) / \mathrm{C}$ ratio increases by a factor of 3 higher than the factor of 1.7 observed for the modification of the d-UNCD $+1+$ PMMA surface by the adsorbed HSA. The trend of protein adsorption parallels that of the hydrophobic character of the

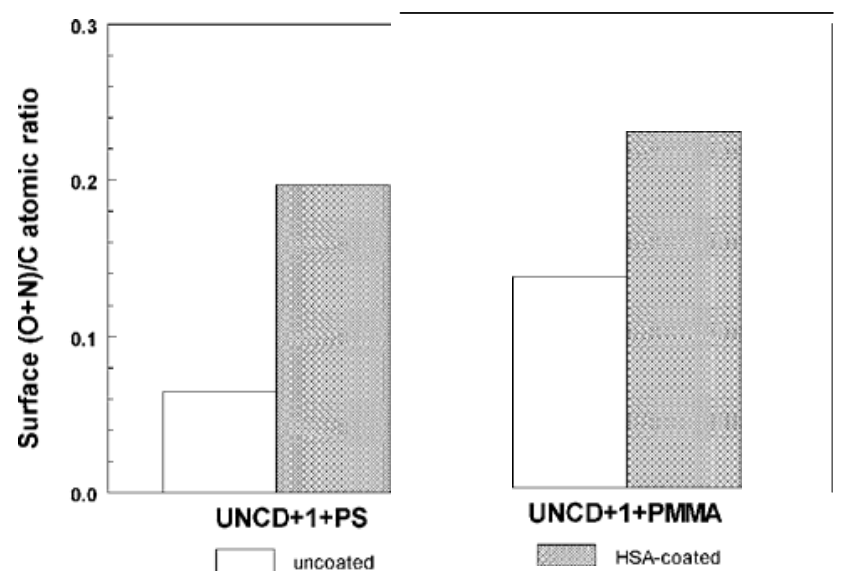

Fig. 4. $(\mathrm{O}+\mathrm{N}) / \mathrm{C}$ atomic ratios determined by XPS for uncoated and HSAcoated d-UNCD+1+PS and d-UNCD+1+PMMA. polymer brushes (PS is more hydrophobic than PMMA [8]) and clearly hydrophobic interactions operate at the proteinbrush-water interface.

\section{Conclusions}

ATRP of methylmethacrylate, styrene was initiated from Ndoped ultrananocrystalline diamond (UNCD) surfaces modified by the electrochemical reduction of a brominated aryl diazonium salt, $\mathrm{BF}_{44}, \mathrm{~N}_{2}-\mathrm{C}_{6} \mathrm{H}_{4}-\mathrm{CH}\left(\mathrm{CH}_{3}\right)-\mathrm{Br}$ (D1). The grafted $-\mathrm{C}_{6} \mathrm{H}_{4}-\mathrm{CH}\left(\mathrm{CH}_{3}\right)-\mathrm{Br}$ acted as ATRP initiator. The PMMA and PS brushes were characterized by XPS and contact angle measurements. The lateral growth of the brushes was found to be homogeneous. Attempts to initiate the ATRP of MMA and styrene from the undoped UNCD was unsuccesful and this is perhaps due to the very negligibly small amount of attached brominated aryl type initiator. Protein adsorption onto the brushes decreased in the order PS $>$ PMMA as judged from XPS measurements, a result that agrees with the superior hydrophobicity of polystyrene.

This paper shows that the "ATRP/diazonium salt" protocol is a valuable approach for the controlled surface modification of materials of technological importance by organic coatings. As biointerfaces are concerned, it is also clear that this novel method can be tuned in order to favour or in contrast to limit protein adsorption. Our very recent studies of the minimization of protein adsorption using hydrophilic copolymers of styrene and polyglycidol grown from glassy carbon plates [38] are indeed encouraging in this sense and shall soon be extended to diamond surfaces. This is of fundamental and technological importance given the development of e.g., diamond-coated implants and biosensors with optimized resitance to non specific adsorption. 


\section{Acknowledgements}

The authors are grateful to the Conseil re'gional d'Ile de France for financial support through the SESAME 2000 scheme. TM wishes to thank the French Ministry of Higher Education for financial support through a PhD studentship. The work at Argonne National Laboratory was supported by the US Department of Energy, Office of Science, Basic Energy Sciences, under Contact No. W-31-109-ENG-38.

\section{References}

[1] K. Matyaszewski, J. Xia, Chem. Rev. 101 (2001) 2921.

[2] S. Edmondson, V.L. Osborne, W.T.S. Huck, Chem. Soc. Rev. 33 (2004) 14.

[3] C. Perruchot, M.A. Khan, A. Kamitsi, S.P. Armes, T. von Werne, T.E. Patten, Langmuir 17 (2001) 4479.

[4] D. Bontempo, K.L. Heredia, B.A. Fish, H.D. Maynard, J. Am. Chem. Soc. 126 (2004) 15372.

[5] D.M. Jones, J.R. Smith, W.T.S. Huck, C. Alexander, Adv. Mater. 14 (2002) 1130.

[6] S.M. Desai, S.S. Solanky, A.B. Mandale, K. Rathore, R.P. Singh, Polymer 44 (2003) 7645.

[7] X. Chen, S.P. Armes, Adv. Mater. 15 (2003) 1558.

[8] T. Matrab, M.M. Chehimi, C. Perruchot, A. Adenier, A. Guillez, M. Save, B. Charleux, E. Cabet-Deliry, J. Pinson, Langmuir 21 (2005) 4686.

[9] J. Pinson, F. Podvorica, Chem. Soc. Rev. 34 (2005) 429.

[10] H. Li, T. Xu, C. Wang, J. Chen, H. Zhou, H. Liu, Appl. Surf. Sci. 249 (2005) 257.

[11] R. Hauert, Diamond Relat. Mater. 12 (2003) 583.

[12]X. Xiao, J. Wang, C. Liu, J.A. Carlisle, B. Mech, R. Greenberg, D. Guven, R. Freda, M.S. Humayun, J. Weiland, O. Auciello, J. Biomed. Mater. Res. B: Appl. Biomater., Published Online: 21 Oct. 2005.

[13]F.A. Armstrong, Encycl. Electrochem. 9 (2002) 11.

[14] J.A. Carlisle, Nat. Mater. 3 (2004) 668.

[15] J.A. Carlisle, O. Auciello, Interface 12 (2003) 28.

[16] J.P. McEvory, J.S. Foord, Electrochim. Acta 50 (2005) 2933.

[17] S.C.H. Kwok, J. Wang, P.K. Chu, Diamond Relat. Mater. 14 (2005) 78.

[18] S. Bhattacharyya, O. Auciello, J. Birrell, J.A. Carlisle, L.A. Curtiss, A.N Goyette, D.M. Gruen, A.R. Krauss, J. Schlueter, A. Sumant, P. Zapol, Appl. Phys. Lett. 79 (2001) 1441.

[19] J. Birrell, J.E. Gerbi, O. Auciello, J. Gibson, D.M. Gruen, J.A. Carlisle, J. Appl. Phys. 93 (2003) 5606.
[21]Q. Chen, D.M. Gruen, A.R. Krauss, T.D. Corrigan, M. Witek, G.M. Swain, J. Electrochem. Soc 148 (2001) E44.

[22] T.N. Rao, I. Yagi, T. Miwa, D.A. Tryk, A. Fujishima, Anal. Chem. 71 (1999) 2506.

[23] C.E. Troupe, I.C. Drummond, C. Graham, J. Grice, P. John, J.I.B. Wilson, M.G. Jubberb, N.A. Morrison, Diamond Relat. Mater. 7 (1998) 575.

[24] T.L. Lasseter, B.H. Clare, N.L. Abbott, R.J. Hamers, J. Am. Chem. Soc. 126 (2004) 10220.

[25] T. Ando, M. Nishitanigamo, R.E. Raweles, K. Yamamoto, M. Kamo, Y. Sato, Diamond Relat. Mater. 5 (1996) 1136.

[26] T. Strother, T. Knickerbocker, J.N. Russell, J.E. Butler, L.M. Smith, R.J. Hamers, Langmuir 18 (2002) 968.

[27] H. Natsu, I. Yagi, T. Tatsuma, D.A. Tryk, A. Fujishima, Electrochem. Solid-State Lett. 2 (1999) 522.

[28] T. Nakamura, T. Ohana, M. Susuki, M. Ishihara, A. Tanaka, Y. Koga, Surf. Sci. 580 (2005) 101.

[29]T. Tsubota, S. Tanii, S. Ida, M. Nagata, Y. Matsumoto, Phys. Chem. Chem. Phys. 5 (2003) 1474.

[30] H. Notsu, T. Fukazawa, T. Tatsuma, D.A. Tryk, A. Fujishima, Electrochem. Solid-State Lett. 4 (2001) H1.

[31] J. Wang, M.A. Firestone, O. Auciello, J.A. Carlisle, Langmuir 20 (2004) 11450.

[32] J.E. Gerbi, O. Auciello, J. Birrell, D.M. Gruen, B.W. Alphenaar, J.A. Carlisle, Appl. Phys. Lett. 83 (2001) 2003.

[33] G. Lombardi, F. Bénédic, F. Mohasseb, K. Hassouni, A. Gicquel, Plasma Sources Sci. Technol. 13 (2004) 375.

[34] G. Cicala, P. Bruno, F. Be'nédic, F. Silva, K. Hassouni, G.S. Senesi, Diamond Relat. Mater. 14 (2005) 421.

[35]F. Bénédic, M.B. Assouar, F. Mohasseb, O. Elmazria, P. Alnot, A. Gicquel, Diamond Relat. Mater. 13 (2004) 347;

P. Bruno, F. Be'nédic, F. Mohasseb, F. Silva, K. Hassouni, Thin Solid Films 482 (2005) 51;

F. Silva, F. Bénédic, P. Bruno, A. Gicquel, Diamond Relat. Mater. 14 (2005) 398.

[36] O.A. Williams, R.B. Jackman, Semicond. Sci. Technol. 18 (2003) S34.

[37] M. Hikita, K. Tanaka, T. Nakamura, T. Kajiyama, A. Takahara, Langmuir 20 (2004) 5304.

[38] H. Kawarada, Surf. Sci. Rep. 26 (1996) 205;

J. Ristein, M. Riedel, F. Maier, B.F. Mantel, M. Stammler, L. Ley, J. Phys., Condens. Matter 13 (2001) 8979;

M. Tachiki, Y. Kaibara, Y. Sumikawa, M. Shigeno, H. Kanazawa, T. Banno, K.S. Song, H. Umezawa, H. Kawarada, Surf. Sci. 581 (2005) 207.

[39] T. Matrab, M.M. Chehimi, J. Pinson, T. Basinska, S. Slomkowski, Surf. Interface Anal., (in press). 